\title{
A comparative study of the effects of risperidone and olanzapine on metabolic parameters of schizophrenic patients
}

\author{
Sanjay B. Nanotkar ${ }^{3}$, Balwant K. Choure ${ }^{1 *}$, Devesh D. Gosavi ${ }^{2}$
}

${ }^{1}$ Department of Pharmacology, RCSM Govt. Medical College Kolhapur, Maharashtra, India ${ }^{2}$ Department of Pharmacology, MGIMS, Sevagram, Wardha, Maharashtra, India ${ }^{3}$ Department of Medicine, MGIMS, Sevagram, Wardha, Maharashtra, India

Received: 01 March 2016

Revised: 09 April 2016

Accepted: 10 May 2016

*Correspondence to:

Dr. Balwant K. Choure,

Email: drchourebk@gmail.com

Copyright: (C) the author(s), publisher and licensee Medip Academy. This is an openaccess article distributed under the terms of the Creative Commons Attribution NonCommercial License, which permits unrestricted noncommercial use, distribution, and reproduction in any

\begin{abstract}
Background: Risperidone and olanzapine are the most commonly prescribed antipsychotic drugs. There is an overwhelming need to look into the adverse effects induced by these drugs; metabolic disturbance being one of the important of them. Metabolic disturbance induced by these drugs is a little searched domain; Most of the literature on their metabolic adverse effects is based on retrospective analysis. Moreover there is a distinct lack of information on the metabolic adverse effects of these drugs in Indian subjects with special reference to rural population.

Methods: The present study was a prospective, open label, observational study conducted on 189 consecutive new subjects who were prescribed either risperidone $(n=93)$ and olanzapine $(n=96)$ in the psychiatry department of a rural medical college and hospital.

Results: Patients on treatment of risperidone $(n=84)$ showed an increase in all the variables except for HDL cholesterol levels which showed fall. The increases in weight, body mass index were found to be extremely significant $(\mathrm{p}<0.001)$. While the rise in the systolic and diastolic blood pressure, fasting sugars and triglycerides, changes was not significant. The fall in HDL cholesterol was not statistically significant.

Conclusions: We conclude from this study that both risperidone and olanzapine have propensity to produce metabolic syndrome in subjects who use them. When compared, olanzapine has a higher chance to produce metabolic syndrome in subjects who were prescribed it, as compared to subjects who were on risperidone.
\end{abstract}

Keywords: Risperidone, Olanzapine, Metabolic, Parameters, BMI, Metabolic syndrome

\section{INTRODUCTION}

Atypical antipsychotics are considered first-line medications for schizophrenia and other psychotic disorders. ${ }^{1}$ They are better tolerated and are superior to typical antipsychotics in terms of persistence and efficacy. $^{2-4}$ Among the atypical antipsychotics, risperidone and olanzapine are the most widely prescribed antipsychotics and have been shown to be well tolerated as well as efficacious in the treatment of psychotic disorders. $^{5-7}$

Risperidone and olanzapine have lower risk of extra pyramidal side effects, they are associated with a different spectrum of side effects some of which may be life threatening. ${ }^{8}$ They are mostly associated with metabolic adverse effects include weight gain, increased risk of diabetes mellitus and hyperlipidemia. ${ }^{9-11}$ Antipsychotic therapy, per say, is a long term venture and ADRs like metabolic adverse effects associated with these drugs often lead to non-compliance, at times discontinuation. ${ }^{12}$

In India, limited efforts are taken on the part of the manufacturer on the ADR monitoring. With a chance of fabricated results of post marketing surveillance, the need of pharmacovigilance efforts stands very high. ${ }^{13}$ Pharmacovigilance studies in India are still in its infancy 
and there are few reports available on ADR profile of antipsychotic agents. ${ }^{13}$ In Psychiatry units, it can play a vital role in detecting metabolic adverse effects and can possibly safeguard the health of the user population. Therefore, there is growing concern among the healthcare personnel to assess the metabolic adverse effects of these atypical antipsychotics, which have an impact on longterm compliance and achieving successful treatment. ${ }^{14,15}$ Many studies have already been done comparing efficacy of risperidone and olanzapine, but the metabolic adverse effects of these drugs are little searched, and the Indian data in this context is relatively sparse. ${ }^{16}$

This prompted us to evaluate the metabolic adverse effects profile of risperidone and olanzapine in our teaching hospital.

\section{METHODS}

\section{Study design}

This was a prospective, observational study carried out on patients attending Psychiatry OPD of a rural based hospital. It was based on active surveillance to assess the metabolic parameters whiles on the therapy with risperidone and olanzapine. The study was started after taking approval from institutional ethics committee. Throughout the study, ethical considerations were followed strictly.

A total of 189 drug naïve patients of either sex; of age between 18 years and 50 years; attending psychiatry OPD, who were prescribed either of the drugs under study i.e. risperidone $(n=93)$ and olanzapine $(n=96)$, irrespective of their diagnosis, were considered for the study. Patients willing to give consent to participate in study were enrolled for the study. Patients with a known or suspected history of substance abuse (including alcohol, nicotine) in the three months preceding screening OR Subjects with history of any significant or unstable cardiovascular, respiratory, renal, hepatic, hematological, endocrine, immunological, or other systemic disease were excluded from the study. Demographic details along with routine physical examination were recorded. A detailed history of the presenting symptoms, other medical or surgical illnesses, co medications, if any at the time of reporting etc. was taken with the help of semi structured, pretested, preformed questionnaire. Blood pressure, weight, height were measured.

The body mass index (BMI) was calculated. As advised by the treating psychiatrist, laboratory investigations like Lipid profile, fasting glucose were carried out. Subjects receiving the drugs under study were evaluated at follow up visits which were scheduled 4 weeks (1 month) after the initial assessment and every 8 weeks ( 2 months) thereafter or at the time when treating psychiatrist asked the patient to come, whichever is earlier. And the investigations were scheduled to be repeated at the end of the study i.e. 6 months. The subjects were maintained on their respective drugs till the completion of study. Final decision regarding to continuation of the drug, decreasing the dose of drug, withholding the drug or whether to change the drug was left to the treating psychiatrist.

\section{Statistical analysis}

Statistical analysis was done using QUICK CALS software. Descriptive analysis of demographic data was expressed as mean \pm SDM and one way ANNOVA test was used to compare the differences among socio demographic characteristics. Means and standard deviations were used to present continuous variables and were compared by z-test. Analysis of the relationship between the drugs and changes in various components of metabolic syndrome was studied using chi square test and "p" value for significance. $\mathrm{P}$ value of less than 0.05 was considered as statistically significant.

\section{RESULTS}

Out of 189 patients registered, 9 patients from risperidone group and 8 patients from olanzapine group were lost to follow-up. A total of 84 patients in risperidone group and 88 patients in olanzapine group completed the six month follow up period of the study.

Table 1: Changes in different indices of metabolic syndrome in subjects on treatment of risperidone ( $n=84)$.

\begin{tabular}{|c|c|c|c|}
\hline \multirow{3}{*}{ Variables } & & ne group $(n=84)$ & \multirow{3}{*}{ P value } \\
\hline & Pre-treatment & Post- treatment & \\
\hline & \multicolumn{2}{|c|}{ Mean \pm SD } & \\
\hline Weight (kg) & $56.26 \pm 6.81$ & $58.01 \pm 7.13$ & $P=0.016$ \\
\hline BMI (kg/m) & $23.45 \pm 1.90$ & $24.18 \pm 2.10$ & $\mathrm{P}=0.028$ \\
\hline \multirow{2}{*}{$\begin{array}{l}\text { Blood pressure } \\
(\mathrm{mmHg})\end{array}$} & $113.5 \pm 7.16$ & $114.38 \pm 8.36$ & $\mathrm{p}=0.10$ \\
\hline & $73.57 \pm 6.50$ & $74.67 \pm 6.57$ & $\mathrm{p}=0.23$ \\
\hline Triglycerides (mg/dl) & $126.78 \pm 10.22$ & $128.58 \pm 11.02$ & $\mathrm{p}=0.08$ \\
\hline HDL cholesterol (mg/dl) & $48.25 \pm 6.00$ & $48.09 \pm 4.98$ & $\mathrm{p}=0.59$ \\
\hline Fasting sugars $(\mathrm{mg} / \mathrm{dl})$ & $87.46 \pm 4.22$ & $88.38 \pm 3.44$ & $\mathrm{p}=0.09$ \\
\hline
\end{tabular}


Patients on treatment of risperidone $(n=84)$ showed an increase in all the variables except for HDL cholesterol levels which showed fall (Table 1). The increase in weight, body mass index were found to be extremely significant $(p<0.001)$. While the rise in the systolic and diastolic blood pressure, fasting sugars and triglycerides, changes was not significant. The fall in HDL cholesterol was not statistically significant.

In olanzapine group, the variables like Weight, Body Mass Index, systolic and diastolic blood pressure, fasting sugars and triglycerides, showed an extremely significant.
Increase after treatment, while the fall in HDL cholesterol was also extremely significant (Table 2).

When the effects of risperidone and olanzapine on metabolic parameters were compared with each other it is found that the differences in the change in weight, body mass index (BMI) and fasting sugars are extremely significant $(\mathrm{P}<0.05)$ with olanzapine showing a higher rise than the risperidone. While the rise in systolic blood pressure and fall in HDL cholesterol are very much significant and changes in diastolic blood pressure and triglycerides are found to be significant statistically (Table 3).

Table 2: Changes in different indices of metabolic syndrome in subjects on treatment of olanzapine $(\mathrm{n}=88)$.

\begin{tabular}{|c|c|c|c|c|}
\hline \multirow{3}{*}{\multicolumn{2}{|c|}{ Variables }} & \multicolumn{2}{|c|}{ Olanzapine group ( $\mathrm{n}=\mathbf{8 8})$} & \multirow{3}{*}{ P value } \\
\hline & & Pre-treatment & Post- treatment & \\
\hline & & \multicolumn{2}{|c|}{ Mean \pm SD } & \\
\hline Weight (kg) & & $56.47 \pm 6.62$ & $61.24 \pm 8.93$ & $\mathrm{p}=0.01$ \\
\hline $\operatorname{BMI}\left(\mathrm{kg} / \mathrm{m}^{2}\right)$ & & $23.51 \pm 1.85$ & $25.48 \pm 2.80$ & $\mathrm{p}=0.045$ \\
\hline \multirow{2}{*}{$\begin{array}{l}\text { Blood pressure } \\
(\mathrm{mmHg})\end{array}$} & SBP & $112.4 \pm 8.16$ & $118.32 \pm 8.90$ & $\mathrm{p}=0.009$ \\
\hline & DBP & $72.42 \pm 6.2$ & $76.7 \pm 6.24$ & $\mathrm{p}=0.008$ \\
\hline \multicolumn{2}{|c|}{ Triglycerides (mg/dl) } & $129.11 \pm 12.40$ & $133.19 \pm 15.36$ & $\mathrm{p}=0.037$ \\
\hline \multicolumn{2}{|c|}{ HDL cholesterol (mg/dl) } & $49.14 \pm 4.56$ & $46.2 \pm 5.61$ & $\mathrm{p}=0.03$ \\
\hline \multicolumn{2}{|c|}{ Fasting sugars (mg/dl) } & $87.4 \pm 4.87$ & $95.08 \pm 6.72$ & $\mathrm{p}=0.026$ \\
\hline
\end{tabular}

Table 3: Comparison of mean changes in different indices of metabolic syndrome in subjects on treatment with olanzapine and risperidone.

\begin{tabular}{|c|c|c|c|}
\hline \multirow{3}{*}{ Variables } & Me & bolic paramets & \multirow{3}{*}{$P$ value } \\
\hline & Risperidone & Olanzapine & \\
\hline & \multicolumn{2}{|c|}{ Mean \pm SD } & \\
\hline Weight (kg) & $1.75 \pm 2.14$ & $4.77 \pm 5.10$ & $\mathrm{p}=0.017$ \\
\hline BMI $\left(\mathrm{kg} / \mathrm{m}^{2}\right)$ & $0.73 \pm 0.89$ & $1.92 \pm 2.11$ & $p=0.034$ \\
\hline \multirow{2}{*}{$\begin{array}{l}\text { Blood pressure } \\
(\mathrm{mmHg})\end{array}$} & $0.88 \pm 8.14$ & $5.91 \pm 10.63$ & $\mathrm{p}=0.009$ \\
\hline & $1.10 \pm 8.53$ & $4.26 \pm 8.55-,-$ & $\mathrm{p}=0.037$ \\
\hline Triglycerides (mg/dl) & $1.79 \pm 9.36$ & $4.08 \pm 16.04$ & $\mathrm{p}=0.045$ \\
\hline HDL cholesterol (mg/dl) & $0.16 \pm 4.29$ & $-3.22 \pm 5.09$ & $\mathrm{p}=0.02$ \\
\hline Fasting sugars (mg/dl) & $0.92 \pm 4.86$ & $7.68 \pm 7.46$ & $\mathrm{p}=0.008$ \\
\hline
\end{tabular}

\section{DISCUSSION}

The recognition that antipsychotic treatment can be associated with deleterious metabolic and other health effects emphasizes the need to address medical aspects of treatment of psychoses. In recent years, mental health care providers have been grappling with issues related to metabolic syndrome associated with antipsychotic treatments in patients of psychotic disorders. Though there is some research done on this aspect of metabolic adverse effects in subjects taking antipsychotics in the west, similar research in the Indian scenario is still in its infancy.
In this study we assessed the changes in weight and various indices of metabolic syndrome viz. body mass index (BMI), blood pressure and levels of HDL cholesterol, triglycerides and fasting glucose in patients of psychotic disorder, who were on antipsychotics, either on risperidone or olanzapine.

When weights of the subjects on the drugs under study (either risperidone or olanzapine) were measured again after 6 months, there was extremely significant increase in weight in both the groups with a mean change of $1.75 \pm 2.14 \mathrm{~kg}$ in the risperidone group and mean change of $4.77 \pm 5.10 \mathrm{~kg}$ in olanzapine. When both the groups were compared, the difference was found to be extremely 
significant with olanzapine showing the higher change. This finding was consistent with others. ${ }^{17,18}$ Our results were also similar to the clinical antipsychotic trials for intervention effectiveness (CATIE). In the CATIE schizophrenia study, where Olanzapine was again associated with greater and more significant weight gain and increases in lipids and glucose. ${ }^{19}$

Weight-gain liability should be factored in when choosing psychotropic medications. Care should also be taken in the choice of concomitant psychiatric medications. In patients who have gained significant weight or developed metabolic complications, all medications should be reviewed from both metabolic and psychiatric perspectives. $^{20}$

One strategy to prevent weight gain and metabolic disturbance or to promote weight loss is to add a medication associated with weight loss to the antipsychotic medication regimen e.g. Orlistat (lipase inhibitor) and Sibutramine (serotonin/dopamine/nor epinephrine reuptake inhibitor) are the only drugs currently approved for long-term weight loss.

Similarly increase in BMI was found to be extremely significant within the group and intergroup. The results of present study are comparable with the results of studies done by Ganguli et al, Garyfallos et al. ${ }^{21,22}$

Serum triglycerides also showed a rise in subjects in both the groups with statistically significant higher change in olanzapine group. This finding is consistent with previous studies. $^{23-26}$

As per the international diabetes federation (IDF 2006) criteria

Table 4: Number of subjects fulfilling the criteria for various components of metabolic syndrome.

\begin{tabular}{|lccccccc|}
\hline \multicolumn{1}{|c}{ Groups } & \multicolumn{2}{c}{ Risperidone } & \multicolumn{3}{c}{ Olanzapine } \\
\hline Pre- & $\begin{array}{l}\text { Post- } \\
\text { Treatment }\end{array}$ & treatment & Diff & $\begin{array}{l}\text { Pre- } \\
\text { Treatment }\end{array}$ & $\begin{array}{l}\text { Post- } \\
\text { treatment }\end{array}$ & Diff \\
\hline BMI $\left(\mathrm{kg} / \mathrm{m}^{2}\right)$ & 0 & 3 & 3 & 1 & 8 & 7 & 0.09 \\
\hline Triglycerides $(\mathrm{mg} / \mathrm{dl})$ & 1 & 6 & 5 & 2 & 12 & 10 & 0.23 \\
\hline HDL cholesterol $(\mathrm{mg} / \mathrm{dl})$ & 4 & 7 & 3 & 3 & 10 & 7 & 0.86 \\
\hline Systolic BP $(\mathrm{mmHg})$ & 0 & 3 & 3 & 1 & 6 & 5 & 0.38 \\
\hline Diastolic BP $(\mathrm{mmHg})$ & 0 & 0 & 0 & 0 & 2 & 2 & 0.07 \\
\hline Fasting sugars $(\mathrm{mg} / \mathrm{dl})$ & 0 & 2 & 2 & 1 & 9 & 8 & 0.98 \\
\hline Metabolic Syndrome & 0 & 3 & 3 & 1 & 6 & 5 & 0.53 \\
\hline
\end{tabular}

Number of subjects having triglycerides levels of 150 $\mathrm{mg} / \mathrm{dl}$ increased from 2 to 12 in subjects treated with olanzapine while the increase was from 1 to 6 in subjects treated with risperidone. Number of subjects having fasting glucose levels of $>100 \mathrm{mg} / \mathrm{dl}$; increased from 1 to 9 in subjects treated with olanzapine while the increase was from 0 to 2 in subjects treated with risperidone. However changes in the number of subjects fulfilling the other components of international diabetes federation (IDF 2006) criteria were not significant ( $p>0.05$ ). In the subjects treated with olanzapine the number of subjects fulfilling the criteria for metabolic syndrome increased from 1 to 6 whereas the same increased from 0 to 3 in subjects treated with risperidone and this difference between the two groups was not found to be significant.

When comparing for the number of subjects fulfilling the raised TG criteria (TG $150 \mathrm{mg} \%$ ), Ooanzapine group had two subjects fulfilling the criteria for raised TG before intervention and the number increased to 12 after intervention. Similarly for risperidone group, there was 1 subject fulfilling the criteria for raised $\mathrm{TG}$ before intervention and the number increased to 6 after intervention. This difference between the antipsychotic groups was not found to be significant. Another component of metabolic syndrome HDL cholesterol also showed an extremely significant $(p<0.001)$ fall in olanzapine group while the fall in HDL cholesterol in risperidone group was found to be insignificant. The difference in the change in HDL cholesterol values in olanzapine group $(-3.22 \pm 5.09 \mathrm{mg} \%)$ and the risperidone group $(0.16 \pm 4.29 \mathrm{mg} \%)$ was found to be very significant with olanzapine showing the greater fall. This fall in HDL levels after these drugs is in concordance with majority of the studies. ${ }^{27-29}$ When comparing the number of subjects fulfilling the criteria for raised HDL-C (as per MS-IDF) criteria, it was found that in olanzapine group, 3 subjects met the criteria before intervention and the number increased to 10 . On the other hand in risperidone group, the number of subjects fulfilling the raised HDL-C criteria increased from 4 to 7 . However on comparing the change in the number of subjects fulfilling the criteria in both groups, it was found that the difference was insignificant. When the blood pressures were assessed, both the systolic and diastolic blood pressures were found to increase in both the groups. In the risperidone group this rise was found to be insignificant. 
In the olanzapine group, the rise of systolic BP and in diastolic BP was found to be extremely significant. The intergroup comparison for these changes was found to be very significant in systolic blood pressure whereas the change in diastolic. Blood pressure was found to be significant with olanzapine showing the higher change. In our study number of subjects having raised BP (SBP or DBP) as per the MS-IDF criteria, increased from 1 to 8 in Olanzapine group as compared to the change in number from 0 to 3 in risperidone group. However this difference in both the groups was not found to be significant. Fasting sugars are one the most important parameters of metabolic syndrome.

In our study, increase in the fasting sugars of the subjects on olanzapine was extremely significant. Although, the rise in fasting sugars in the risperidone group, was statistically insignificant. The difference between the changes in blood sugars in two groups was also found to be extremely significant.

This finding of raised blood sugars is similar to the findings of Gautam et al. ${ }^{28}$ Similarly in the clinical antipsychotic trials for intervention effectiveness (CATIE) schizophrenia study, the groups demonstrated significant differences in weight gain and significant glucose metabolism changes (with olanzapine resulting in the greatest negative effect). In phase 2, compared with the other agents, olanzapine was again associated with greater and more significant weight gain and increases in lipids and glucose. In our study, number of subjects having raised fasting sugars $(100 \mathrm{mg} \%)$ as per the MSIDF criteria, increased from 1 to 9 in olanzapine group and the same increased from 0 to 2 in risperidone group. The comparison of this change in number of subjects, in two groups was found to be insignificant statistically.

When measuring the change in the subjects fulfilling the entire criteria for the metabolic syndrome, it was found that no subjects fulfilled the MS-IDF criteria for the metabolic syndrome at the baseline in the risperidone group and there was only one subject in the olanzapine group fulfilling the criteria for metabolic syndrome. However at the final measurement, there were 6 subjects in the olanzapine group and 3 subjects in the risperidone group fulfilling the criteria for the metabolic syndrome. Though numerically, olanzapine appeared to be causing more metabolic disturbances, the difference was not found to be statistically significant. The findings of our study are in line with other studies done previously. ${ }^{30,31}$

Our study showed that the patients under treatment of olanzapine were more prone to develop metabolic syndrome as compared to the patients taking risperidone treatment.

However, as the duration of the study was limited. Moreover the results need to be extrapolated using a much bigger sample size.

\section{Impact of the study}

This imparting of knowledge can definitely help in curbing cost of treatment, better clinical outcome and compliance of the patients.

Our study will definitely contribute in generating the hospital ADR- metabolic adverse effects database. This can further help in improving the knowledge about the existing metabolic adverse effects resulting in change in the attitude of physicians and patients resulting in better Pharmacovigilance practices.

We can further envisage that irrespective of which antipsychotic the subject is on, what is needed is a systematic and regular monitoring of various metabolic parameters and taking prompt intervention steps when any of the metabolic parameters are found deranged. Since the patients with metabolic syndrome are more prone for sudden cardiac death, thromboembolic disorders, cerebrovascular disease hence clinicians should be aware of this potential fatal adverse effects.

\section{CONCLUSION}

We conclude from this study that both risperidone and olanzapine have propensity to cause metabolic syndrome in subjects who use them. When compared, olanzapine has marginally higher chance to produce metabolic syndrome in subjects who were prescribed it, as compared to subjects who were on risperidone.

Funding: No funding sources Conflict of interest: None declared

Ethical approval: The study was approved by the Institutional Ethics Committee

\section{REFERENCES}

1. Bhanji NH, Tempier R, Bhanji NH TR. Managing schizophrenia during the stable phase: Is there consensus among practice guidelines? Can J psychiatry. 2002;47(1):47.

2. Wahlbeck K, Tuunainen A, Ahokas ALS. Dropout rates in randomised antipsychotic drug trials. Psychopharmacology. 2001;155:230-3.

3. Glick IBP. Time to study discontinuation, relapse, and compliance with atypical or conventional antipsychotics in schizophrenia and related disorders. International clinical psychopharmacology. 2002; $17: 65-8$.

4. Davis JM, Chen NGI, Davis JM, Chen N, Glick ID. A meta-analysis of the efficacy of second-generation antipsychotics. Arch Gen Psychiatry. 2003;60(6):553-64.

5. Conley RR. A randomized double-blind study of risperidone and olanzapine in the treatment of schizophrenia or schizoaffective disorder. Am J Psychiatry. 2001;158:765-74. 
6. Marder SR, Davis JM CG, Marder SR, Davis JM, Chouinard G. The effects of risperidone on the five dimensions of schizophrenia derived by factor analysis: combined results of the North American trials. J Clin Psychiatry. 1997;58(12):538-46.

7. Tollefson GD, Beasley CM, Tran PV, Street JS, Krueger JA, Tamura RN, et al. Olanzapine versus haloperidol in the treatment of schizophrenia and schizoaffective and schizophreniform disorders: results of an international collaborative trial. Am J Psychiatry. 1997; 154:457-65.

8. Aronson JK. Risk perception in drug therapy. 2006;135-7.

9. Allison DB, Mentore JL, Heo M, Chandler LP, Cappelleri JC, Infante MC, et al. Antipsychoticinduced weight gain: a comprehensive research synthesis. Am J Psychiatry. 1999;156(11):1686-96.

10. Wirshing DA, Spellberg BJ, Erhart SM, Marder SR, Wirshing WC. Novel antipsychotics and new onset diabetes. Biol Psychiatry. 1998;44(8):778-83.

11. Meyer JM. A retrospective comparison of weight, lipid, and glucose changes between risperidone- and olanzapine treated inpatients: metabolic outcomes after 1 year. J Clin Psychiatry. 2002;63(5):425-33.

12. Cooper C, Bebbington $P$, King M, Brugha T, Meltzer $\mathrm{H}$, Bhugra D, et al. Why people do not take their psychotropic drugs as prescribed: results of the 2000 national psychiatric morbidity survey. Acta Psychiatr Scand. 2007;116(1):47-53.

13. Lingeswaran A, Harshashetty, Kigshuklohan, Amitparamel SG. A letter to the editor. Ind J Ppharmacol. 2010;42.

14. Sussman N. Review of atypical antipsychotics and weight gain. J Clin Psychiatry. 2001;62(2):5-12.

15. Meyer JM, Koro CE. The effects of antipsychotic therapy on serum lipids: a comprehensive review. Schizophr Res. 2004;70(1):1-17.

16. Ingole S, Belorkar NR, Waradkar P, Shrivastava M. Comparison of effects of olanzapine and risperidone on body mass index and blood sugar level in schizophrenic patients. Indian J Physiol Pharmacol. 2009;53(1):47-54.

17. Newcomer JW. Second-generation (atypical) antipsychotics and metabolic effects: a comprehensive literature review. CNS Drugs. 2005;19(1):1-93.

18. Henderson DC, Daley TB, Kunkel L, RodriguesScott M, Koul P, Hayden D. Clozapine and hypertension: a chart review of 82 patients. J Clin Psychiatry. 2004;65(5):686-9.

19. Nasrallah HA. Atypical antipsychotic-induced metabolic side effects: insights from receptor-binding profiles. Mol Psychiatry. 2008;13(1):27-35.

20. Faulkner G, Cohn TA. Pharmacologic and nonpharmacologic strategies for weight gain and metabolic disturbance in patients treated with antipsychotic medications. Can J Psychiatry. 2006;51(8):502-11.

21. Garyfallos G, Dimelis D, Kouniakis P, Sidiropoulos N, Karastergiou A, Lavrentiadis G, et al. Olanzapine versus risperidone: weight gain and elevation of serum triglyceride levels. Eur Psychiatry. 2003;18(6):320-1.

22. Ganguli R, Brar JS, Ayrton Z. Weight gain over 4 months in schizophrenia patients: a comparison of olanzapine and risperidone. Schizophr Res. 2001;49(3):261-7.

23. Saari K, Koponen H, Laitinen J, Jokelainen J, Lauren $\mathrm{L}$, Isohanni $\mathrm{M}$, et al. Hyperlipidemia in persons using antipsychotic medication: a general population-based birth cohort study. J Clin Psychiatry. 2004;65(4):547-50.

24. Osser DN, Najarian DM, Dufresne RL. Olanzapine increases weight and serum triglyceride levels. J Clin Psychiatry. 1999;60(11):767-70.

25. Sheitman BB, Bird PM, Binz W, Akinli L, Sanchez C. Olanzapine-induced elevation of plasma triglyceride levels. Am J Psychiatry. 1999;156(9):1471-2.

26. Stroup TS, Lieberman JA, McEvoy JP, Swartz MS, Davis SM, Capuano GA, et al. Effectiveness of olanzapine, quetiapine, and risperidone in patients with chronic schizophrenia after discontinuing perphenazine: a CATIE study. Am J Psychiatry. 2007;164(3):415-27.

27. Baptista T, Lacruz A, Angeles F, Silvera R, de Mendoza S, Mendoza MT, et al. Endocrine and metabolic abnormalities involved in obesity associated with typical antipsychotic drug administration. Pharmacopsychiatry. 2001;34(6):223-31.

28. Gautam S, Meena PS. Drug-emergent metabolic syndrome in patients with schizophrenia receiving atypical (second-generation) antipsychotics. Indian J Psychiatry. 2011;53(2):128-33.

29. Kinon BJ, Liu-Seifert H, Ahl J, Ahmed S, Baker RW. Longitudinal effect of olanzapine on fasting serum lipids: a randomized, prospective, 4-month study. Ann N Y Acad Sci. 2004;1032:295-6.

30. Krane-Gartiser K, Breum L, Glumrr C, Linneberg A, Madsen M, Koster A, et al. Prevalence of the metabolic syndrome in Danish psychiatric outpatients treated with antipsychotics. Nord J Psychiatry. 2011;65(5):345-52.

31. Cerit C, Vural M, Bos Gelmez SU, Ozten E, Aker AT, Yildiz M. Metabolic syndrome with different antipsychotics: a multicentre cross-sectional study. Psychopharmacol Bull. 2010;43(4):22-36.

Cite this article as: Nanotkar SB, Choure BK, Gosavi DD. A comparative study of the effects of risperidone and olanzapine on metabolic parameters of schizophrenic patients. Int J Basic Clin Pharmacol 2016;5:814-9. 